\title{
Retrospective analysis of junior female handball players' priorities
}

\author{
Frolova L. S., Timofeev A. A., Petrenko Y. A., Atamas' O. A., Grechukha S. V., Gun'ko P. N., Suprunovich V. A.
} The Bohdan Khmelnytsky National University of Cherkasy, Ukraine

\begin{abstract}
Purpose:

fulfillment of retrospective analysis of junior female handball players' tactic priorities.

Material: $\quad$ in the research junior female handball players of $15-16$ yrs age $(n=60)$ participated. The researches were conducted in 2006, 2010 and 2016 on the base of sport schools and physical culture colleges of Ukraine. We used author's programs «Balltest» and «Handball skills».

Results: $\quad$ indicators of junior female handball players' abilities and tactical thinking effectiveness in different periods of the research were received. Correlations of these indicators with physical potentials and throw fitness point at tactical priorities of the players. Comparative characteristic showed that junior female handball players of 2016 year of the research had better abilities for solution of complex team tasks with low sensor indicators. We found handball players' preferences to defensive and attacking actions in central zone of site.

Conclusions: by universal character of tactic priorities junior female handball players of 2016 year of the research yield to the players of 2006 and 2010 years of the research. Junior female handball players of 2016 year of the research prevail in successful mental solution of position defense tactic tasks, especially in readiness to act as supporters.

Keywords: junior female handball players, tactical priorities, tactical thinking, situational thinking, attack, defense.
\end{abstract}

\section{Introduction}

Striving for show value and records, modern sports reached the level of athletes' contest at extreme of human potentials. Such athletes' performances are pointed at a fan as an active participant of sport action [4]. Spectator has a demand - to enjoy the fight of opponents. In this case show value of sports is defined as "fight of characters and tactical plans" [4]. Especially it is noticeable in team kinds of sports. By the words of D. Alberto Lorenzo Calvo [19], sport game teams have their own concept of success. It implies individual sportsmanship of players and their actions' coordination in constantly changing site situations and resistance of opponent [19]. To ensure such activity in handball the players shall have the following: quickness of perception [39]; ability to predict situations, solve them and take adequate solutions [5]; to have cognitive abilities $[17,18,20]$.

Analysis of scientific works showed that study of athlete's cognitive abilities is still an urgent problem. Such studies have different orientation:

Study of efficient team thinking, based on non-verbal, emotional solutions [39];

Tactical thinking with expected feedback of the taken decision. In this case intuitive, analytical and subjectively oriented models of game situations are used [44];

Intuitive thinking as quicker and more effective mean of taking correct decision in definite game episode [41];

Emotional component of decision-taking. It is necessary for developing of own behavioral style and confidence in critical game situations $[22,38]$;

Testing of perceptive-cognitive differences between age groups, licenses levels of different age coaches [28];

Correlation between motivation, purpose and perception level of motivation climate and their influence on cognitive and somatic components of young athletes'

(c) Frolova L. S., Timofeev A. A., Petrenko Y. A., Atamas' O. A., Grechukha S. V., Gun'ko P. N., Suprunovich V. A. , 2017 doi:10.15561/18189172.2017.0503 contest anxiety [27, 30];

Success in training of general and special physical qualities at different stages of athletes' training [31];

Impulse and subjective indicators of athletes' reaction to physical load [37];

Indicators for prediction of martial arts athletes successes $[35,40]$;

Optimization of physical loads [34] considering athletes' individual characteristics [25, 26] and health indicators [42].

Other works were directed at solution of problem of athletes' cognitive sphere. They expanded knowledge about handball players' tactical thinking [10, 12, 13]. Tactical thinking is defined as ability to choose rational decision in game situation [14]. It is a complex of brain operations, ensured by potentials of human supreme nervous system's activity [8] and individual-typological specificities of neuro-physiological processes [10]. The method of handball players' tactical thinking definition was worked out on the base of these principles [3]. It included game situations' models, which were displayed with variant of complex and simple tasks' solution. Usage of virtual board for dynamic presentation of tactic tasks is shown in other methodic [17, 44]. This methodic is characterized by the presence of program algorithm and division into blocks.

Among other researches one can find the following tactical models of athletes' and teams' behavior:

Methodology of assessment of tactical attacking behavior in handball [32];

Usage of gradient contest. The authors found that usage of gradient contest can increase success of students with higher and lower qualification level [33];

Working out of strategy: for prevention from young athletes, who are trained in elite educational structures, "burning out"; for facilitating long term participation and increase of welfare in sport activity [36]. 
Tactical thinking is a part of athlete's cognitive strategies [6]. There is interconnection of anthropometric, technical and physical indicators of an athlete and realization of his/her tactical plan [15, 19, 43]. Computer program permits to find tactical preferences of elite female handball players for controlling over competition functioning [13]. Usage of such program in case of junior female handball players will provide information about tactical priorities. In its turn, it will permit to raise effectiveness of training process.

The purpose of the work is to fulfill retrospective analysis of junior female handball players' tactic priorities by their tactical thinking, considering physical indicators and throw fitness. For this purpose it is necessary: 1) to study characteristics of tactical thinking, physical indicators and throw fitness of different research periods' junior female handball players; 2) determine tactical preferences of junior female handball players to actions in different game situations.

\section{Material and methods}

Participants: retrospective analysis was fulfilled on identical by age and qualification groups of junior female handball players tested in different periods. In the research junior female handball players of $15-16$ yrs ( $1^{\text {st }}$ sport category) participated. 20 athletes, tested in 2006 and 22 - tested in 2010 - pupils of Zaporozhye and Krivoy Rog sport schools; 18 athletes, tested in 2016, were the students of Kherson and Brovary higher physical culture colleges. The researches were conducted in leading handball schools, which successfully train athletes for teams of masters and combined teams of Ukraine. All participants gave consent for participation in the research.

Organization of the research: junior female handball players were tested by computer program «Handball skills» [13]. The program is based on two tests for handball players' tactical thinking. These tests were worked out with the help of virtual board for presentation of different complexity game situations' schemes. First test «Balltest» [3] consisted of 4 blocks: tactical thinking in attack; tactical thinking in defense; situational thinking in attack and situational thinking in defense. Each block consisted of 100 schemes with variants of solution, which were positively assessed by experts. In the process of testing 15 game situations, arbitrary chosen by computer, were displayed. Every schema was displayed during 7.33 sec. for analysis and taking decision. By blocks we determined

Table 1. Fitness of junior female handball players coefficient of thinking, mean time of correct decisiontaking and calculated effectiveness of thinking. The methodic of tactical thinking finding was experimentally tested on handball players, basketball players and football players of different age. Informative value and reliability of this methodic has been proved in other researches [1, $10,13]$.

The second test [12] included 400 schemes from «Balltest». The test consisted of three blocks: situations in left, right and central parts of site. 30 schemes of game situations, arbitrary chosen by computer, were displayed (10 situations for every zone). On the base of coefficient and mean time of correct decision taking we determined territory priority of players' tactical thinking [12].

In creation of «Handball skills» computer program tactical thinking indicators and main factors, which to the largest extent influence on players' mental actions in different game situations, were considered. They are: body parameters, quickness and accuracy of throws. That is why in formulas of «Handball skills» program the following indicators were introduced: tactical thinking; body length; speed of 28 meters' run; accuracy and quickness of four throws from 7 meters' distance to squares $40 \times 40 \mathrm{~cm}$ (special screen). At the end of experiment we received information, which permitted to find territorial and tactical preferences of junior female handball players.

Statistical analysis: all experimental data were processed with the help of Excel program.

\section{Results}

Before solution of tactical task athletes create own mental plan of actions. Mental planning is interconnected with tactical thinking and player's potentials in realization of his/her ideas. It forms players' tactical priorities. Our methodic of tactical priorities determination is not intended for preparation of handball player to game with definite opponent. The methodic informs about mental tactical schema of actions, which can be effectively used by a coach.

We provide the data of junior female handball players' tactical priorities in retrospective analysis, which are not connected with game with definite opponent. We compared junior female handball players' indicators of 2006, 2010 and 2016 years of the research. Analysis of the data showed that in 2006 and 2010 years indicators of junior female handball players did not differ noticeably. That is why we present results of 2006 and 2016 years

\begin{tabular}{lll}
\hline & \multicolumn{2}{l}{ Periods of the research } \\
Description of indicators & $\begin{array}{l}\mathbf{2 0 0 6} \text { year } \\
(\mathbf{n = 2 0 )}\end{array}$ & $\begin{array}{l}\mathbf{2 0 1 6} \text { year } \\
(\mathbf{n = 1 8 )}\end{array}$ \\
\hline Accuracy of 7 meters' throws from 4 (quantity) & $2,78 \pm 0,17$ & $1,61 \pm 0,21^{*}$ \\
Time of 7 meters throws' fulfillment (sec.) & $4,67 \pm 0,20$ & $6,68 \pm 0,28^{*}$ \\
Time of 28 meters' distance run (sec.) & $4,59 \pm 0,15$ & $4,61 \pm 0,12$ \\
Body length (cm) & $169,6 \pm 1,42$ & $167,5 \pm 1,36$ \\
\hline
\end{tabular}

Note: ${ }^{*} p<0.05$ - comparing with indicators of 2006 
of the research. Difference between indicators was determined in respect to the second group of the tested.

In the process of the researches we found no distinctions in body length and quickness. But handball players of 2006 year of the research had better throw fitness by accuracy by $42 \%$ and by quickness - by $43 \%$ (see table 1).

Junior female handball players, tested in 2016, demonstrated higher qualitative indicators of tactical thinking in attack - by $54 \%$ and in defense - by $45 \%$ (solution of complex tactic multiple tasks). Handball players, tested in 2006, had better quality of situational thinking in attack - by $21 \%$ and in defense - by $37 \%$ (solution of simple tasks). Both groups had equal quality of thinking in attack. With it, handball players of $2006 \mathrm{had}$ better quality of thinking in defense by $6 \%$ (see table 2 ).

Junior female handball players, tested in 2006, demonstrated quickness of correct decision taking in situational tasks' solution in attack by $11 \%$ and in defense - by $12 \%$. Quickness of tactical tasks' solution (independent on game phase) was equal (see table 3).

Junior female handball players, tested in 2006, demonstrated higher effectiveness of situational tasks' solution in attack - by $28 \%$ and tactical tasks in attack
- by $31 \%$. Effectiveness of situational tasks' solution in defense was on the same level. The players, tested in 2016, had effectiveness of tactical thinking in defense by $60 \%$ higher (see table 4 ).

There is no difference between indicators of the tested groups by territorial advantage in left and right site zones. The players of 2016 were better in central zone by $54 \%$. In group of 2006 priorities by zones were not found. Junior female handball players, tested in 2016, demonstrated higher quality of tasks' solution in central part of site: by $37 \%$ in left and by $48 \%$ in right zones (see table 5).

In tactical priorities of 2016 junior female handball players we found the following: preferences to actions in left and right zones was lower by $15 \%$; territorial universality of attacking actions - by $10 \%$ and preconditions for attacks were higher in central zone by $10 \%$ (see table 6).

Sportswomen of 2016 had lower indicators of territorial universality of defense actions by $20 \%$ and defense actions with outcome - by $24 \%$. They have higher indicators in central zone by $20 \%$ and interaction in support - by $24 \%$. Readiness for group actions in all tested groups is equal.

In tactical priorities to team actions in attack the bent

Table 2. Qualitative indicators of junior female handball players' tactical thinking

\begin{tabular}{lll}
\hline Description of indicators (quantity of correct answers) & $\begin{array}{l}\text { Periods of the research } \\
\mathbf{2 0 0 6} \text { year } \\
\text { (n=20) }\end{array}$ & $\begin{array}{l}\mathbf{2 0 1 6} \text { year } \\
\text { (n=18) }\end{array}$ \\
\hline Situational thinking in attack & $9,21 \pm 0,62$ & $7,28 \pm 0,50^{*}$ \\
Tactical thinking in attack & $4,58 \pm 0,63$ & $7,06 \pm 0,38^{*}$ \\
Situational thinking in defense & $6,25 \pm 0,54$ & $3,94 \pm 0,45^{*}$ \\
Tactical thinking in defense & $3,92 \pm 0,27$ & $5,67 \pm 0,25^{*}$ \\
\hline
\end{tabular}

Note: ${ }^{*} p<0.05$ - comparing with indicators of 2006

Table 3. Quickness of decision taking by junior female handball players

\begin{tabular}{lll}
\hline Description of indicators & $\begin{array}{l}\text { Periods of the research } \\
\mathbf{2 0 0 6} \text { year } \\
(\mathbf{n = 2 0 )}\end{array}$ & $\begin{array}{l}\mathbf{2 0 1 6} \text { year } \\
(\mathbf{n = 1 8 )}\end{array}$ \\
\hline Situational thinking in attack & $3,38 \pm 0,12$ & $3,76 \pm 0,19 *$ \\
Tactical thinking in attack & $3,31 \pm 0,18$ & $4,08 \pm 0,68$ \\
Situational thinking in defense & $3,85 \pm 0,16$ & $4,31 \pm 0,17^{*}$ \\
Tactical thinking in defense & $4,36 \pm 0,17$ & $4,11 \pm 0,18$ \\
\hline
\end{tabular}

Note: ${ }^{*} p<0.05$ - comparing with indicators of 2006

Table 4. Effectiveness of junior female handball players' tactical thinking

\begin{tabular}{lll}
\hline Description of indicators & $\begin{array}{l}\text { Periods of the research } \\
\mathbf{2 0 0 6} \text { year } \\
(\mathbf{n = 2 0 )}\end{array}$ & $\begin{array}{l}\mathbf{2 0 1 6} \text { year } \\
(\mathbf{n}=\mathbf{1 8})\end{array}$ \\
\hline Situational thinking in attack & $18,17 \pm 0,92$ & $13,00 \pm 0,87^{*}$ \\
Tactical thinking in attack & $9,22 \pm 0,73$ & $6,39 \pm 0,85^{*}$ \\
Situational thinking in defense & $10,82 \pm 0,88$ & $11,83 \pm 0,78$ \\
Tactical thinking in defense & $5,99 \pm 0,51$ & $9,61 \pm 0,67^{*}$ \\
\hline
\end{tabular}

Note: ${ }^{*} p<0.05$ - comparing with indicators of 2006 
Table 5. Territorial priority of tactical tasks' solution by junior female handball players

\begin{tabular}{lll}
\hline & \multicolumn{2}{l}{ Periods of the research } \\
Description of indicators (quantity of correct answers) & $\begin{array}{l}\mathbf{2 0 0 6} \text { year } \\
(\mathbf{n = 2 0 )}\end{array}$ & $\begin{array}{l}\mathbf{2 0 1 6} \text { year } \\
\text { (n=18) }\end{array}$ \\
\hline Solution of tactical tasks in central zone & $\mathbf{7 , 0 8 \pm 0 , 5 4}$ & $10,89 \pm 0,89 *$ \\
Solution of tactical tasks in left zone & $6,95 \pm 0,46$ & $6,86 \pm 0,42$ \\
Solution of tactical tasks in right zone & $6,19 \pm 0,42$ & $5,72 \pm 0,48$ \\
\hline
\end{tabular}

Note: ${ }^{*} p<0.05$ - comparing with indicators of 2006

Table 6. Tactical priorities of junior female handball players

\begin{tabular}{llc}
\hline & Periods of the research \\
Description of indicators, (\%) & $\mathbf{2 0 0 6}$ year & $\begin{array}{l}\mathbf{2 0 1 6} \text { year } \\
\text { (n=18) }\end{array}$ \\
\hline Bent to attacks in central zone of site & 20,00 & 40,00 \\
Bent to attacks in left zone of site & 25,00 & 10,00 \\
Bent to attacks in right zone of site & 25,00 & 10,00 \\
Territorial universality of attacks & 30,00 & 20,00 \\
Bent to defense actions in central zone of site & 40,00 & 60,00 \\
Bent to defense actions in left zone of site & 10,00 & 10,00 \\
Bent to defense actions in right zone of site & 10,00 & 10,00 \\
Territorial universality of defense actions & 40,00 & 20,00 \\
Readiness to active defense with outcome & 30,00 & 5,56 \\
Readiness to defense on line & 10,00 & 10,00 \\
Readiness for support & 60,00 & 84,44 \\
Bent to improvising in attacks & 55,00 & 55,56 \\
Tactical universality in attacks & 15,00 & 16,67 \\
Bent for realization of standard schemes in attacks & 30,00 & 27,78 \\
Bent to improvising in defense & 5,00 & 5,56 \\
Tactical universality in defense & 80,00 & 16,67 \\
Bent for realization of standard schemes in defense & 15,00 & 77,78 \\
\hline
\end{tabular}

and readiness for different plans of actions was on the same level. $55 \%$ of handball players plan to improvise; $30 \%$ think to act by coach's plan and $15 \%$ demonstrated universality.

In both tested groups we received the same indicators of bent to improvising in defense. Sportswomen of 2016 demonstrated higher readiness for standard actions in defense by $63 \%$ and lower bent to universality of actions by $79 \%$.

\section{Discussion}

Results of our researches comply with high requirements to handball players' intellectual sphere, put forward by high contest of teams on international level [5]. The received data confirm the opinion [5] that in conditions of strong contest handball players shall be able to promptly perceive large volume of different signals. Our results confirm the importance of cognitive strategies for athletes [6] and show their presence in female handball players. The results, received by «Handball skills» program [13] demonstrate tactical priorities of junior female handball players on the base of tactical thinking coordination, considering physical and technical parameters. The study of tactical thinking was fulfilled with the help of virtual board for dynamic presentation of tactical tasks [3]. Other program models with virtual board for presentation of game situation differ from method «Balltest»: slide tests [17] and video tests [41] for handball players; video tests for basketball players «BasketballTest» [1], video model for football players [18]. They imply presentation of situations in the forms of photos or video segments of real games. The mentioned program models included analysis of game situation, prediction of actions, intuition. M. Raab, S. Laborde [41] point at advantages of handball players' intuitive solutions in complex and unknown situations. V.A. Tishchenko, A.A. Shipenko [11] are sure in significant influence of players' anticipation on effectiveness of tactic actions. We think that intuition and anticipation shall be excluded from indicators of tactic thinking. Methodic «Balltest» offers stand displaying of schemes instead of real game's fragments.

Comparison of «Balltest» methodic with other programs showed their distinctions. In works of P. Weigel, M. Raab, R. Wollny [44] program model DEMATS (decision making in team sports) is presented. The 
model includes device for recording visual perception of game moment. It permits to register individual speed of information's perception. «Balltest» methodic does not envisage additional devices. Sensor component of tactical thinking we determine by mean time of correct answers. A Y. Cardin, C. Bossard, C. Buche, G. Kermarrec [21] worked out virtual simulator of football ball CoPeFoot, which stipulates complex registration of decision making elements. Random selection of players does not consider emotional empathy factor that can influence on adequacy of the made decision in phases with ball. «Balltest» methodic is intended for individual testing that permits to avoid emotional empathy influence. By the data of $\mathrm{Z}$. Certel, Z. Bahadir, T. Sönmez Gül [22] in female handball empathy in respect to current emotional state of other player is rather high.

The received by us data about tactical thinking confirm the data of other scientists [21, 24] about dynamic character of game situations in time aspect. Qualitative indicators of tactical thinking witness about changes in mental planning of players' actions. In 2006 and 2010 junior female handball players successfully solved situational tasks, which were based on individual-group actions with simple choice of decision (independent on game phase). In 2016 they solved more successfully the tasks in attacks, independent on complexity of game situation. Other authors [5, 9] note that attacking actions prevail over defense of high effectiveness. I. T. Gasanov [2] and V. Tsyganok [16] specify changes in tactic and positional attacks, where individual actions with quick transition dominate.

In the researches of 2016 we obtained indicators of high effectiveness of situational and tactical thinking in defense. It permits for junior female handball players to successfully solve defensive positional tasks. It is in agreement with opinion of T. Debanne, V. Angel, P. Fontayne [24] that junior athletes' coaches prefer defensive strategy of tactical training. Such strategy can reflect in athletes' mental plans. Collective game in defense with some moments of individual realization of tactic task creates difficulties for opponent [20, 24].

Study of tactical thinking sensor components showed that quickness of decision making in complex game situations does not differ in the tested groups. Junior female handball players, tested in 2016, were slow in solution of simple tasks with little quantity of players. Other data [17] show that quickness of decision making in team tasks is higher that quickness of thinking about decision. Here we can appeal to Z. Certel, Z. Bahadir, T. Sönmez Gül [22], who noted that for young athletes alert style of decision making is characteristic. This style includes carefulness and reasonability of complex situations' assessment.

For junior handball players of 2016 it was difficult to limit time for fulfillment 7 meters' throws. They had low accuracy and great time losses. Short time for information processing by junior athletes negatively influences on actions and reduces their effectiveness [44].

Study of territorial priority in tactical tasks' solution showed that focusing on central zone is characteristic for all tested groups. But they are more expressed in 2016. These data are confirmed by the data of other researches $[7,23]$. With constant players' concentration in center their actions' elements are better perceived.

In tactical priorities of junior female handball players, tested in 2016, we observed bent to successful solution of tasks in the center of site (independent on game phase). As L. Červar [23] notes dynamic game requires quickness of tactic responding. But the players' cognitive potentials $[39,44]$ do not permit to successfully solve the tasks in complex and badly known zones of site. N. Rogulj, V. Srhoj, L. Srhoj [43] note that limited physical or technical data of players correct their functioning. It influences on thinking stereotype [44]. In tactical priority of junior female handball players, tested in 2016, there is readiness to realize standard schemes in defense. To improvise [29] it is necessary to be ready for variable actions. It requires ability to think in space from athlete. In junior female handball players cognitive and emotional uncertainty appears due to high responsibility in defense [22]. That is why the game by standard tactical schemes permits to observe tactical plan of coach [24]. It releases pressure on decision making [29].

\section{Conclusions}

We found tactical priorities of junior female handball players in different research periods by tactical thinking indicators, considering physical potentials and throw fitness. We determined, that handball players, tested in 2016, universality in tactical preferences yield to players of 2006 and 2010. Junior female handball players, tested in 2016, have higher bent to solve tactical tasks in central zone of site in attack and defense as well as to solve tactical tasks of positional defense. They also are ready to act on support. In junior female handball players of 2006 and 2010 we observed abilities for successful solution of tactical tasks, which do not depend on site zone. They are ready: to defend with outcome and on support; to improvise in attack.

\section{Acknowledgements}

The work has been fulfilled by scientific group in compliance with plan of scientific research works by topic "Theoretical methodic principles of mobilization readiness of different qualification athletes" (state registration № 0116 u 003858).

\section{Conflict of interests}

The authors declare that there is no conflict of interests. 


\section{Reference}

1. Bazilevs'kij AG. Indicators of tactical fitness in attack and defense of 10-13 yrs. basketball players. Naukovopedagogichni problemi fizichnoi kul'turi, 2015;57:21-23. (in Ukrainian)

2. Gasanov IT. Special aspects of handball teams attacking actions' structure in handball. Uchenye zapiski universiteta imeni P. F. Lesgafta, 2008;1(35):25-29. (in Russian)

3. Glazirin ID, Frolova LS, Suprunovich VO. Method of psycho-physiological characteristics' determination for assessment of athletes' special fitness in team sport games. Patent Ukraine u200806398. 2009. Aug 28. (in Ukrainian)

4. Ermilova VV, Krotova EE. Show aspects of sports and their transformation in conditions of modern society. Terra Humana, 2015;2(35):100-103. (in Russian)

5. Kirichenko VF, Shalaev OS, Geras'kin AA. Characteristic features of modern handball. In: Physical culture and sports in students'life. Omsk; 2015. P. 9-10. (in Russian)

6. Korobejnikova LG. Study of perception and information processing cognitive strategies in elite athletes. Visnik problem biologii i medicini, 2014;4(1):344-348. (in Ukrainian)

7. Mel'nik VA. Perfection of handball players'attacking tactic actions at stage of preparation for high achievements. Cand. Diss. Lviv; 2015. (in Ukrainian)

8. Petrenko IuO, Men'shikh OE. Neuro-dynamic and psychic functions of primary school age children with different physical condition: theory and practice. Cherkasy: CHNU; 2014. (in Ukrainian)

9. Serdiuk DG. Perfection of elite handball players' technicaltactic actions on the base of competition activity's indicators. Cand. Diss. Dnipro; 2016. (in Ukrainian)

10.Suprunovich VO, Frolova LS. Individual-typological aspects of tactical thinking in football players of different sex. Visnik Pridniprov'ia, 2013;3:59-61. (in Ukrainian)

11.Tishchenko VA, Shipenko AA. Study of elite handball players' psycho-physiological state. Izvestiia Tul'skogo gosudarstvennogo universiteta. 2015;4:169-172. (in Ukrainian)

12.Frolova LS, Glazirin ID, Petrenko IuO. Method of determination of field players' game-role in team sport games. Patent Ukraine a201301171. 2006. Sep 29. (in Ukrainian)

13.Frolova LS, Glazirin ID, Petrenko IuO. Control over female handball players' competition functioning with the help of interactive technologies. Pedagogics, psychology, medical-biological problems of physical training and sports, 2012;4:107-113.

14.Frolova LS, Glazirin ID, Petrenko YO, Kharchenko IA, Timofeev AA, Goncharenko AN, Garyachuk OV. Properties of playing and tactical thinking of female handball players with different qualification. Pedagogics, psychology, medical-biological problems of physical training and sports, 2013; 17(1): 84-90. doi:10.6084/m9.figshare.106945

15.Frolova LS, Glazirin ID, Petrenko YO, Suprunovich VO, Menshikh EE, Kharchenko IA, Pivnenko AO. Effect of psychophysical state on different qualification's handball players on their preparedness. Physical education of students, 2013; 17(3): 72-74. doi:10.6084/m9.figshare.663630

16.Ciganok V. Modern ideas about theory of tactical training perfection in handball. Trenerskaia akademiia. 2010;1:1015. (in Russian)

17.Abdedaim A, Boumesjed A, Sebbane M. Application of simulation to study decision making in handball. European Scientific Journal, 2013;9(24):326-333.

18.Buszard T, Farrow D, Kemp J. Examining the influence of acute instructional approaches on the decision-making performance of experienced team field sport players. $J$ Sports Sci. 2013;31:238-47.

19.Calvo Lorenzo D. Alberto. The detection of talent in collective sports. Revista universitaria de la actividad física y el deporte. 2002;1:15-23. (In Spanish)

20.Canadian Team Handball Federation. Team Handball Long Term Athlete Development Model. For the Period 20102015, 2014.

21.Cardin Y, Bossard C, Buche C, Kermarrec G. Investigate Naturalistic Decision-Making of Football Players in Virtual Environment. Paper presented at International Conference on Naturalistic Decision Making. Marseille; 2013. P. 109-17.

22.Certel Z, Bahadir Z, Sönmez Gül T. Investigation of empathy and self-esteem in decision making and decision-making styles among those who played team sport. University Journal of Physical Education and Sport Sciences 2013;7(1):16-27.

23.Červar L. The future of handball [document on the Internet]. 2015. [cited 2017 Febr 15]. Available from: http://www. eurohandball.com/article/023884

24.Debanne T, Angel V, Fontayne P. Decision-Making during Games by Professional Handball Coaches Using Regulatory Focus Theory. Journal of Applied Sport Psychology, 2014;26:111-124.

25.Druz VA, Iermakov SS, Artemyeva GP, Puhach YI, Muszkieta R. Individualization factors of students' physical education at modern stage of its realization. Physical education of students, 2017; 21(1): 10-16. doi:10.15561/20755279.2017.0102

26.Druz VA, Iermakov SS, Nosko MO, Shesterova LYe, Novitskaya NA. The problems of students' physical training individualization. Pedagogics, psychology, medicalbiological problems of physical training and sports, 2017; 21(2): 4-12. doi:10.15561/18189172.2017.0201

27.Fedak SS, Afonin VM, Nebozhuk OR, Lashta VB, Romaniv IV, Dzyama VV, Pylypchak IV. Functional fitness level of military college cadets. Pedagogics, psychology, medicalbiological problems of physical training and sports, 2016; 20(6): 34-40. doi:10.15561/18189172.2016.0605

28.Fischer L, Baker J, Rienhoff R, Strauss B, Tirp J, Busch D, et al. Perceptual-cognitive expertise of handball coaches in their young and middle adult years. J Sport Sci. 2016;34(17):163742.

29.García Antón Dr Juan L. Tactical and strategical alternatives against anticipation defense to dangerous distance's shooters [document on the Internet]; 2014. [cited 2017 Febr 12]. Available from: https://ru.scribd.com/document/310333063/ Tactical-and-Strategical-Against-Shooters

30.Garcia-Mas A, Fuster-Parra P, Ponseti FJ, Palou P, Olmedilla A, Cruz J. A Bayesian Analysis of the motivation, motivational climate and anxiety in young competitive team players. Anales De Psicologia. 2015;31(1):355-66.

31.Gaskov AV, Kuzmin VA, Kudryavtsev DM, Iermakov SS. Successfulness of general and special physical qualities' development on different stage of students-boxers' training. Physical Education of Students. 2016;20(1):4-11. 10.15561/20755279.2016.0101

32.Hassan A, Schrapf N, Ramadan W, Tilp M. Evaluation of tactical training in team handball by means of artificial neural networks. J Sport Sci. 2017;35(7):642-7.

33.Hastie PA, Ward JK, Brock SJ. Effect of graded competition on student opportunities for participation and success rates during a season of Sport Education. Physical Education and Sport Pedagogy. 2017;22(3):316-27.

34.Iermakov SS, Arziutov GN, Jagiello W. Quick training of students to judo techniques. Archives of Budo. 2016;12:1524.

35.Iermakov SS, Podrigalo LV, Jagiello W. Hand-grip strength 
as an indicator for predicting the success in martial arts athletes. Archives of Budo. 2016;12:179-86.

36.Isoard-Gautheur S, Guillet-Descas E, Gustafsson H. Athlete Burnout and the Risk of Dropout Among Young Elite Handball Players. Sport Psychologist. 2016;30(2):123-30.

37.Kozina ZL, Iermakov SS, Kadutskaya LA, Sobyanin FI, Krzeminski M, Sobko IN, Ryepko OA. Comparative characteristic of correlation between pulse subjective indicators of girl students' and school girls' reaction to physical load. Physical Education of Students. 2016;20(4):2434. doi:10.15561/20755279.2016.0403

38.Lopatenko GO. Influence of extra training means on effectiveness of fencers' technical tactic actions. Pedagogics, psychology, medical-biological problems of physical training and sports, 2016; 20(3): 41-46. doi:10.15561/18189172.2016.0306

39.Moesch K. Psychological momentum in handball: Doctor. diss. Sweden: Lund University; 2015.

40.Podrigalo LV, Galashko M N, Iermakov SS, Rovnaya OA, Bulashev AY. Prognostication of successfulness in armwrestling on the base of morphological functional indicators' analysis. Physical education of students, 2017; 21(1): 46-51. doi:10.15561/20755279.2017.0108

41.Raab M, Laborde S. When to Blink and When to Think: Preference for Intuitive Decisions Results in Faster and Better Tactical Choices. Research Quarterly for Exercise and Sport 2011;82: 89-98.

42.Radziminska A, Weber-Rajek M, Lulinska-Kuklik E, Kazmierczak U, Moska W. Academic youth's health behavior. Physical education of students, 2016; 20(6): 55-62. doi:10.15561/20755279.2016.0607

43.Rogulj N, Srhoj V, Srhoj L. The Contribution of Collective Attack Tactics in Differentiating Handball Score Efficiency. International Journal Collegium Antropologicum, 2004;28(2):739-746

44.Weigel P, Raab M, Wollny R. Tactical Decision Making in Team Sports - A Model of Cognitive Processes. International Journal of Sports Science, 2015;5(4):128-138.

\section{Information about the authors:}

Frolova L. S.; http://orcid.org/0000-0003-0763-7509; I-f2014@ukr.net; The Bohdan Khmelnytsky National University of Cherkasy; 81 Shevchenko blvd., c. Cherkasy, 18031, Ukraine.

Timofeev A. A.; http://orcid.org/0000-0002-9851-0257; 13tim@i.ua; The Bohdan Khmelnytsky National University of Cherkasy; 81 Shevchenko blvd., c. Cherkasy, 18031, Ukraine.

Petrenko Y. A.; http://orcid.org/0000-0002-6348-2110; petrenko62@gmail.com; The Bohdan Khmelnytsky National University of Cherkasy; 81 Shevchenko blvd., c. Cherkasy, 18031, Ukraine.

Atamas' O. A.; http://orcid.org/0000-0003-4711-5211; helga_atamas@i.ua; The Bohdan Khmelnytsky National University of Cherkasy; 81 Shevchenko blvd., c. Cherkasy, 18031, Ukraine.

Grechukha S. V.; http://orcid.org/0000-0002-3094-8025; sg1050@ukr.net; The Bohdan Khmelnytsky National University of Cherkasy; 81 Shevchenko blvd., c. Cherkasy, 18031, Ukraine.

Gun'ko P. N.; http://orcid.org/0000-0002-0609-8550; gunkopeter@bigmir.net; The Bohdan Khmelnytsky National University of Cherkasy; 81 Shevchenko blvd., c. Cherkasy, 18031, Ukraine.

Suprunovich V. A.; http://orcid.org/0000-0003-0238-5066; ViktoryS1987@ukr.net; The Bohdan Khmelnytsky National University of Cherkasy; 81 Shevchenko blvd., c. Cherkasy, 18031, Ukraine.

Cite this article as: Frolova LS, Timofeev AA, Petrenko YA, Atamas' OA, Grechukha SV, Gun'ko P.N, Suprunovich V.A. Retrospective analysis of junior female handball players' priorities. Pedagogics, psychology, medical-biological problems of physical training and sports, 2017;21(5):214-220. doi:10.15561/18189172.2017.0503

The electronic version of this article is the complete one and can be found online at: http://www.sportpedagogy.org.ua/index.php/PPS/issue/archive

This is an Open Access article distributed under the terms of the Creative Commons Attribution License, which permits unrestricted use, distribution, and reproduction in any medium, provided the original work is properly cited (http://creativecommons.org/licenses/by/4.0/deed.en).

Received: 30.03 .2017

Accepted: 15.04.2017; Published: 25.09.2017 